\title{
High Failure Rate after Beta-tricalcium Phosphate Grafting for the Treatment of Femoral Head Osteonecrosis: a Retrospective Analysis
}

\section{Research article}

Keywords:

Posted Date: January 24th, 2022

DOI: https://doi.org/10.21203/rs.2.20868/v5

License: (c) (i) This work is licensed under a Creative Commons Attribution 4.0 International License. Read Full License

Version of Record: A version of this preprint was published at BMC Musculoskeletal Disorders on April 27th, 2020. See the published version at https://doi.org/10.1186/s12891-020-03291-5.

\section{EDITORIAL NOTE:}

24 January 2022: The published version of this preprint was retracted from BMC Musculoskeletal Disorders on 24 May 2021. The retraction notice can be found here. Research Square has withdrawn this preprint. 


\section{Abstract}

Research Square has withdrawn this preprint. Please see Editorial Note for details.

\section{Full Text}

Research Square has withdrawn this preprint. Please see Editorial Note for details. 